\title{
An Inventory Decision Model When Demand Follows Innovation Diffusion Process under Effect of Technological Substitution
}

\author{
K. K. Aggarwal, Chandra K. Jaggi, and Alok Kumar \\ Department of Operational Research, Faculty of Mathematical Sciences, New Academic Block, University of Delhi, Delhi 110007, India \\ Correspondence should be addressed to Alok Kumar; alok_20_or@yahoo.co.in
}

Received 14 April 2013; Revised 3 September 2013; Accepted 10 September 2013

Academic Editor: S. Dempe

Copyright @ 2013 K. K. Aggarwal et al. This is an open access article distributed under the Creative Commons Attribution License, which permits unrestricted use, distribution, and reproduction in any medium, provided the original work is properly cited.

\begin{abstract}
The concept of marketing literature, especially innovation diffusion concept, plays a pivotal role in developing EOQ models in the field of inventory management. The integration of marketing parameters, especially the idea of diffusion of new products with the inventory models, makes the models more realistic which is most essential while building the economic ordering policies of the products. Also, because of rapid technological development, the diffusion of technology can also be viewed as an evolutionary process of replacement of an old technology by a new one. Therefore, the effect of technological substitution along with the diffusion of new products must be taken into account while formulating economic ordering policies in an inventory model. In this paper, a mathematical model has been developed for obtaining the Economic Order Quantity (EOQ) in which the demand of the product is assumed to follow an innovation diffusion process as proposed by Fourt and WoodLock (1960). The idea of effect of technological substitution of products has been incorporated in the demand model to make the economic ordering policies more realistic. A numerical example with sensitivity analysis of the optimal solution with respect to different parameters of the system is performed to illustrate the effectiveness of the model.
\end{abstract}

\section{Introduction}

Technological breakthroughs are continuously being experienced in every field of business management and because of this new, products are constantly entering into the market system. Also, the penetration of new products into the market system generally come in successive generations. This happens due to speedy technological progress because of rapid development of information and communication technology market. The impact of globalization plays one of the pivotal roles to spread awareness about the new products among societies. Also, the changing needs of the society increases the demand of new products which encourage innovations of the products. Therefore, the theory of innovation diffusion is highly desired for attentive management of the new products in order to minimize the total cost and maximize the benefits. To make the business fascinating and demanding, the importance of innovations in business and industry is highly significant. The innovations, especially technological innovations, have made the firms to upgrade their products skillfully for surviving in the market. Diffusion is defined as the process by which an innovation is communicated through certain channels over time among members of a social system (Rogers [1]). The various diffusion processes have been studied in the literature, which are as follows. The pure innovative model has been considered by Fourt and WoodLock [2] whereas Fisher and Pry [3] explain the pure imitative model. The Bass Model [4] admits both the innovative and imitative aspects of product adoption. The Bass Model [4], introduced over three decades ago, has been widely used in marketing by Peres et al. [5], Parker [6], Rogers [1,7], and Peres et al. [8] and Mahajan et al. [9]. The periodic review inventory model with demand influenced by promotion decisions has been considered by Cheng and Sethi [10]. Kalish [11] has discussed an adoption model of a New Product with Price advertising and uncertainty. Mahajan and Robert [12] have studied Innovation Diffusion in a Dynamic Potential Adopter Population. Sharif and Ramanathan [13, 14] 


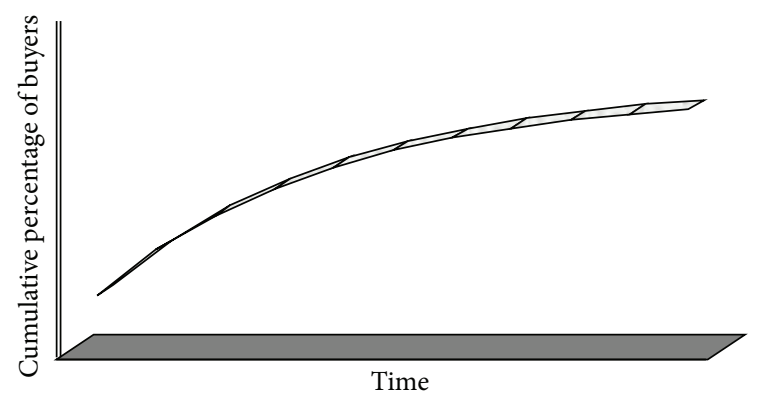

Figure 1: Fourt and WoodLock Curve (Source: Lilien et al. [38]).

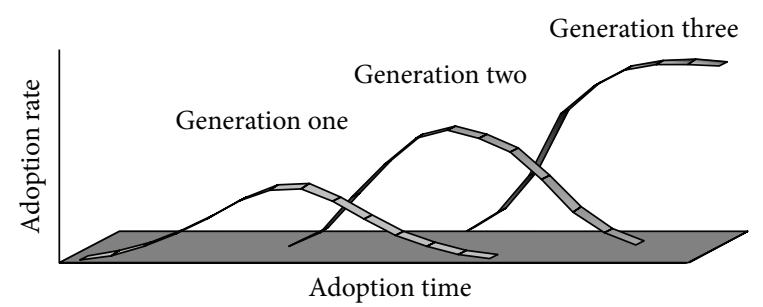

FIGURE 2: Series of technological generations (Source: Norton and Bass [15]).

have considered the application of dynamic potential adopter diffusion model through their study of diffusion of oral contraceptives in Thailand. The diffusion process in terms of number of customers who have bought the product by time " $t$ " has been explained by a modified exponential curve (Figure 1) by Fourt and WoodLock [2]. This model captures the innovative characteristic with its coefficient " $p$ " as the coefficient of innovation.

Also, diffusion of new products cannot be justified without taking into account the effects of successive generations of products because an important feature of most modern new technologies is that they come in successive generations. New products are substituted with more advanced products and technological generations which creates heterogeneity in the adopting population. Moreover, it is observed that any given generation of technology will end up being replaced by a new generation. The old products are not straight away replaced by the new products because of constant innovation, but new products intend to substitute and start competing with the old products which creates parallel diffusion of both the old and the new products in the market. This makes the decreasing pattern of diffusion of old products. The series of technological generations have been well explained through the Figure 2. There are lots of models in the marketing literature which have considered the importance of generation of products. Norton and Bass [15] model is a standard example of multiple generation model, which assumes that the coefficients of innovation and imitation remain unchanged from generation to generation of technology. Norton and Bass [15] is basically based upon the Bass model. The Bass model is also extended by Mahajan and Muller [16] who proposed a model to capture substitution and diffusion patterns for each successive generation of technological products. Speece and
Maclachlan [17] and Danaher et al. [18] incorporated price as an explanatory variable in their model. Islam and Meade [19] proposed that the coefficients of later generation technology are constant increment/decrement over the coefficients of the first generation. Kim et al. [20] developed a model and tried to include intergenerational linkages among successive generations within a product category. Bayus [21] developed a model for consumer sales of second-generation products by incorporating replacement behavior of first generation adopters and suggested different dynamic pricing policies of second-generation consumer durables. Bardhan and Chanda [22] have developed a mathematical model for adoption of successive generations of a high technology product. Chanda and Bardhan [23] developed a model on dynamic optimal advertising expenditure strategies of two successive generations of consumer durables. Bardhan and Chanda [24] also developed a mathematical model for diffusion of products with multiple generations of a high technology product. The above discussed models are well explained in the marketing literature and are extremely significant in the estimation of new products having successive generation features. These models are highly useful in making the Economic inventory policy of any organization as far as new products along with its successive generations are concerned. Unfortunately, the concept of the above marketing models has not been integrated with traditional inventory models which is highly desired while making the economic ordering policy for new products with successive generation features. Though there are some inventory models described below which have incorporated the concept of innovation diffusion in their demand functions, but these models do not consider the effect of diminishing nature of demand rate when the substitute products are entered into the market because of technological innovations which are popularly known as the successive generations of the products. Chanda and Kumar [25] have explained the economic order quantity model with demand influenced by dynamic innovation effect. Aggarwal et al. [26] have considered the EOQ model with innovation diffusion criterion having dynamic potential market size. Also, Chanda and Kumar [27] explain the EOQ model having demand influenced by innovation diffusion criterion under inflationary condition. Chern et al. [28] have formulated the economic order quantity model in which the demand follows innovation diffusion criterion as considered by Bass [4]. Aggarwal et al. [29] formulated an inventory model for new product when demand follows dynamic innovation process having dynamic potential market size. Kumar et al. [30] discussed economic order quantity model under fuzzy sense when the demand follows Bass's innovation diffusion process. Aggarwal et al. [31] have developed an economic order quantity model under fuzzy sense when demand follows innovation diffusion process having dynamic potential market size. The approach in this paper is to focus on the effect of innovation factor on adoption behavior of consumers with the effect of technological substitution of the products. The uniqueness of this model is to make an economic inventory policy of a new product under the condition of its diminishing demand after a certain interval of time when its substitute product enters into the market 
because of technological innovation. The paper is divided into the model development, special case, numerical examples with sensitivity analysis, observations, and managerial implications. Finally, the paper concludes with a discussion on the application, extension, and limitations of the model.

Assumptions. Inventory model has been developed under the following assumptions.

(i) The replenishment rate is infinite, and thus, replenishments are instantaneous.

(ii) Lead time is zero.

(iii) The planning horizon is finite.

(iv) Shortages are not allowed.

(v) Demand rate is time dependent governed by innovation diffusion process and is affected by the introduction of substitute products because of technological innovations.

(vi) The size of the potential market of total number of adopters remains constant. Here, the potential market size includes the number of initial purchases for the time interval for which replacement purchases are excluded.

(vii) The coefficient of innovation remains constant, that is, the likelihood that somebody who is not yet using the product will start using it because of mass media coverage or other external factors will act as constant throughout the cycle length.

(viii) There is only one product bought per new adopter.

(ix) The innovation's sales are confined to a single geographic area.

(x) The impact of marketing strategies by the innovator is adequately captured by the model's parameters.

Notations. Notations used in the modeling framework are as follows:

A: ordering cost

$C$ : unit cost

$I$ : inventory carrying charge

IC: inventory carrying cost

$T$ : length of the replenishment cycle

$T_{1}$ : time of introduction of second generation product

$\theta$ : rate of diminishing demand of first generation product

$p$ : coefficient of innovation

$Q$ : number of items received at the beginning of the period

$K(T)$ : the total cost of the system per unit time

$I(t)$ : on hand inventory at any time $t$

$n(t)=\lambda(t)=S(t)$ : the number of adoptions at time $t$, that is, Demand at time $t$

$\bar{N}$ : potential market size
$N(t)$ : cumulative number of adopters at time $t$

$f(t)$ : the likelihood of purchase at time $t$

$F(t)$ : the cumulative fraction of adopters at time $t$.

\section{Mathematical Model}

The basic assumption considered by different researchers in marketing literature for a fundamental diffusion model is that the rate of diffusion or the number of adopters at any given point in time is directly proportional to the number of remaining potential adopters at that moment. Mathematically, this can be represented as follows:

$$
n(t)=\frac{d N(t)}{d t}=g(t)\{\bar{N}-N(t)\}
$$

where $g(t)$ is known as the rate of adoption or individual probability of adoption.

It has also been assumed that $g(t)$ depends on time through a linear function of $N(t)$ (Mahajan and Peterson [32]). Hence,

$$
n(t)=\frac{d N(t)}{d t}=(a+b N(t))\{\bar{N}-N(t)\}, \quad a \geq 0, \quad b \geq 0 .
$$

Depending on the importance of each source of influence, different versions can be derived from the fundamental diffusion model (Mahajan and Peterson [32]).

When $b=0$, the model only considers external influence, when $a=0$, the model only considers internal influence. When $a \neq 0$ and $b \neq 0$, the resulting model is called a mixed influence diffusion model (Ruiz-Conde et al. [33]).

The basic assumptions used in the Bass Model are that the adoption of a new product spreads through a population primarily due to contact with prior adopters. Hence, the probability that an initial purchase occurs at time $t$, given that no purchase has occurred, is a linear function of the number of previous buyers; that is

$$
\frac{f(t)}{1-F(t)}=p+q F(t) .
$$

If we define $n(t)=\bar{N} f(t)$ and $N(t)=\bar{N} F(t)$ we can express (3) as follows:

$$
n(t)=\frac{d N(t)}{d t}=\left(p+q \frac{N(t)}{\bar{N}}\right)\{\bar{N}-N(t)\} .
$$

Equation (4) is a mixed influence diffusion model. Consider a case of diffusion model of external influence only (taking $q=0$ ) as proposed by Fourt and WoodLock [2], (4) can be defined as follows:

$$
n(t)=\frac{d N(t)}{d t}=p\{\bar{N}-N(t)\}
$$

The basic demand model that has been used in the EOQ model is based on the following assumptions. 
(i) Adoptions take place due to innovation-diffusion effect and it is influenced by the innovation-effect (mass media), that is, external influence only.

(ii) Adoptions of the first generation product is diminishing by the introduction of the second generation product.

Here, the diffusion of new products which is spread through the external influence has been considered for making economic ordering policies of the products. The demand of first generation products, that is, products which are supposed to be introduced at the beginning of the planning period also known as old products, is affected (diminished) due to introduction of the second generation products, that is, products which are supposed to be new in comparison to the first generation products and affecting the demand of old products because of technological innovations after a certain interval of time. Therefore, using the above assumptions, explanations, and (5), the following demand function has been constructed for our model:

$\lambda(t)$

$$
= \begin{cases}p\{\bar{N}-N(t)\}, & 0 \leq t<T_{1}, p \geq \theta, \\ p\{\bar{N}-N(t)\}-\theta\{\bar{N}-N(t)\}, & T_{1} \leq t \leq T, p \geq \theta .\end{cases}
$$

The above demand model shows that the inventory level is depleted wholly due to demand of the old products with a particular pace depending on the parameters associated with it up to time period $T_{1}$ and after time $T_{1}$ and up to time period $T$ the rate of decreasing inventory level is somewhat less than what was experienced before time $T_{1}$ because some demand of the old products are satisfied (substituted) by the new products introduced after time period $T_{1}$ because of technological innovations. The demand usage $\lambda(t)$ which is a function of time plays pivotal role to shrink the inventory size over a period of time. If in the time interval $(t, t+d t)$ the inventory size is dipping at the rate $\lambda(t) d t$, then the total reduction in the inventory size during the time interval $d t$ can be given by $-d I(t)=\lambda(t) d t$. Thus, the differential equation describing the instantaneous state of the inventory level at any time $t, I(t)$ in the interval $(0, T)$ is given by

$$
\frac{d I(t)}{d t}=-\lambda(t) ; \quad 0 \leq t \leq T
$$

where

$$
\begin{aligned}
& \lambda(t) \\
& =n(t)=\frac{d N(t)}{d t} \\
& = \begin{cases}p\{\bar{N}-N(t)\}, & 0 \leq t<T_{1}, p \geq \theta, \\
p\{\bar{N}-N(t)\}-\theta\{\bar{N}-N(t)\}, & T_{1} \leq t \leq T, p \geq \theta,\end{cases} \\
& \Longrightarrow N(t)= \begin{cases}\bar{N}\left(1-e^{-p t}\right), & 0 \leq t<T_{1}, \\
\bar{N}-\left\{\bar{N}-N\left(T_{1}\right)\right\} e^{(p-\theta)\left(T_{1}-t\right)}, & T_{1} \leq t \leq T .\end{cases}
\end{aligned}
$$

Now by model assumption, replenishment is instantaneous and shortages are not allowed. Thus, the inventory level at the initial point of the planning horizon can be assumed to be the cumulative adoption of the product during the cycle time $T$. Hence,

$$
\begin{gathered}
I(0)=Q=\int_{0}^{T} \lambda(t) d t \\
\Longrightarrow I(0)=Q=\bar{N}\left(1-e^{-p T_{1}}\right)+\left[N\left(T_{1}\right)-\bar{N}\right] \\
\times\left(e^{(p-\theta)\left(T_{1}-T\right)}-1\right) .
\end{gathered}
$$

The solution of the differential equation (7) is

$$
I(t)= \begin{cases}I(0)-\bar{N}\left(1-e^{-p t}\right), & 0 \leq t<T_{1}, \\ {\left[\bar{N}-N\left(T_{1}\right)\right]} & \\ \quad \times\left[e^{(p-\theta)\left(T_{1}-t\right)}-e^{-(p-\theta)\left(T_{1}-T\right)}\right], & T_{1} \leq t \leq T .\end{cases}
$$

Now,

$$
\begin{aligned}
& \int_{0}^{T} I(t) d t=\int_{0}^{T_{1}} I(t) d t+\int_{T_{1}}^{T} I(t) d t \\
& \Longrightarrow \int_{0}^{T} I(t) d t= T_{1} I(0)+\frac{\bar{N}}{p}\left[1-e^{-p T_{1}}\right] \\
&-\bar{N} T_{1}+\left[\bar{N}-N\left(T_{1}\right)\right] \\
& \times\left[\frac{e^{(p-\theta)\left(T_{1}-T\right)}-1}{(\theta-p)}+\left(T_{1}-T\right) e^{(p-\theta)\left(T_{1}-T\right)}\right] .
\end{aligned}
$$

The different cost elements involved in the inventory system per unit time can be defined as

Ordering cost per unit time $=\frac{A}{T}$,

Material cost per unit time $=\frac{Q C}{T}$,

$$
\begin{aligned}
= & \frac{C}{T} \bar{N}\left(1-e^{-p T_{1}}\right) \\
& +\left(\frac{C}{T}\right)\left[N\left(T_{1}\right)-\bar{N}\right]\left(e^{(p-\theta)\left(T_{1}-T\right)}-1\right),
\end{aligned}
$$

Cost of carrying inventory per unit time

$$
=\frac{I C}{T} \int_{0}^{T} I(t) d t
$$




$$
\begin{aligned}
= & \left(\frac{I C}{T}\right) T_{1} I(0)+\frac{I C \bar{N}}{p T}\left[1-e^{-p T_{1}}\right] \\
& -\left(\frac{I C}{T}\right) \bar{N} T_{1} \\
& +\left(\frac{I C}{T}\right)\left[\bar{N}-N\left(T_{1}\right)\right] \\
& \times\left[\frac{e^{(p-\theta)\left(T_{1}-T\right)}-1}{(\theta-p)}+\left(T_{1}-T\right) e^{(p-\theta)\left(T_{1}-T\right)}\right] .
\end{aligned}
$$

Thus, the total cost of the inventory system per unit time $K(T)$ is

$$
\begin{aligned}
& K(T)=(14)+(16)+(18) \\
\Longrightarrow K(T)= & \frac{A}{T}+\left[N\left(T_{1}\right)-\bar{N}\right]\left(e^{(p-\theta)\left(T_{1}-T\right)}-1\right) \\
& \times\left(\frac{C}{T}\right)\left(1+I T_{1}\right)+\bar{N}\left(1-e^{-p T_{1}}\right)\left(\frac{C}{T}\right) \\
& \times\left(1+I T_{1}\right)+\frac{I C \bar{N}}{p T}\left[1-e^{-p T_{1}}\right]-\left(\frac{I C}{T}\right) \bar{N} T_{1} \\
& +\left(\frac{I C}{T}\right)\left[\bar{N}-N\left(T_{1}\right)\right] \\
& \times\left[\frac{e^{(p-\theta)\left(T_{1}-T\right)}-1}{(\theta-p)}+\left(T_{1}-T\right) e^{(p-\theta)\left(T_{1}-T\right)}\right] .
\end{aligned}
$$

The necessary criterion for $K(T)$ to be minimum is

$$
\begin{aligned}
\frac{d K(T)}{d T}=0 \\
\Longrightarrow \frac{-A}{T^{2}}+\left[N\left(T_{1}\right)-\bar{N}\right]\left(e^{(p-\theta)\left(T_{1}-T\right)}-1\right)\left(\frac{-C}{T^{2}}\right)\left(1+I T_{1}\right) \\
-\left(\frac{C}{T^{2}}\right)\left(1+I T_{1}\right) \bar{N}\left(1-e^{-p T_{1}}\right) \\
+\left(\frac{C}{T}\right)\left(1+I T_{1}\right)\left[N\left(T_{1}\right)-\bar{N}\right](\theta-p) e^{(p-\theta)\left(T_{1}-T\right)} \\
-\frac{I C \bar{N}}{p T^{2}}\left[1-e^{-p T_{1}}\right]+\left(\frac{I C}{T^{2}}\right) \bar{N} T_{1} \\
+\left(\frac{-I C}{T^{2}}\right)\left[\bar{N}-N\left(T_{1}\right)\right] \\
\times\left[\frac{e^{(p-\theta)\left(T_{1}-T\right)}-1}{(\theta-p)}+\left(T_{1}-T\right) e^{(p-\theta)\left(T_{1}-T\right)}\right] \\
+\left(\frac{I C}{T}\right)\left[\bar{N}-N\left(T_{1}\right)\right] \\
\times\left(T_{1}-T\right)(\theta-p) e^{(p-\theta)\left(T_{1}-T\right)}=0 .
\end{aligned}
$$

Now, for $K(T)$ to be convex:

$$
\begin{aligned}
& \left.\frac{d^{2} K(T)}{d T^{2}}\right|_{T=T^{*}}>0 \\
\Longrightarrow & \frac{2 A}{T^{* 3}}+\left(\frac{2 C}{T^{* 3}}\right)\left(1+I T_{1}\right) \bar{N}\left(1-e^{-p T_{1}}\right) \\
+ & {\left[N\left(T_{1}\right)-\bar{N}\right]\left(e^{(p-\theta)\left(T_{1}-T^{*}\right)}-1\right)\left(\frac{2 C}{T^{3}}\right)\left(1+I T_{1}\right) } \\
& +\left(\frac{C}{T^{*}}\right)\left(1+I T_{1}\right)\left[N\left(T_{1}\right)-\bar{N}\right](\theta-p)^{2} e^{(p-\theta)\left(T_{1}-T^{*}\right)} \\
& +\frac{2 I C \bar{N}}{p^{* 3}}\left[1-e^{-p T_{1}}\right]+\left(\frac{2 I C}{T^{* 3}}\right)\left[\bar{N}-N\left(T_{1}\right)\right] \\
& \times\left[\frac{e^{(p-\theta)\left(T_{1}-T^{*}\right)}-1}{(\theta-p)}+\left(T_{1}-T^{*}\right) e^{(p-\theta)\left(T_{1}-T^{*}\right)}\right] \\
& +\left(\frac{I C}{T^{*}}\right)\left[\bar{N}-N\left(T_{1}\right)\right]\left(T_{1}-T^{*}\right) \\
& \times(\theta-p)^{2} e^{(p-\theta)\left(T_{1}-T^{*}\right)} \\
> & \left(\frac{2 C}{T^{* 2}}\right)\left(1+I T_{1}\right)\left[N\left(T_{1}\right)-\bar{N}\right] \\
& \times(\theta-p) e^{(p-\theta)\left(T_{1}-T\right)}+\left(\frac{2 I C}{T^{* 3}}\right) \bar{N} T_{1} \\
& +\left(\frac{2 I C}{T^{*}}\right)\left[\bar{N}-N\left(T_{1}\right)\right]\left[(\theta-p) e^{(p-\theta)\left(T_{1}-T^{*}\right)}\right] . \\
& \times\left[\left(T_{1}-T^{* 2}\right)(\theta-p) e^{(p-\theta)\left(T_{1}-T^{*}\right)}\right] \\
& {\left[\left(T_{1}\right)\right] }
\end{aligned}
$$

The solution of the equation $d K(T) / d T=0$ gives the optimum value of $T$ provided it satisfies the condition $d^{2} K(T) / d T^{2}>0$. Since the above cost equation (21) is highly nonlinear, the problem has been solved numerically for given parameter values. The solution gives the optimum value $T^{*}$ of the replenishment cycle time $T$. Once $T^{*}$ is known, the value of optimum order quantity $\mathrm{Q}^{*}$ and the optimum cost $K\left(T^{*}\right)$ can easily be obtained from (10) and (19), respectively. The numerical solution for the given base value has been obtained by using software packages Lingo and Excel-Solver.

2.1. Special Case. When $\theta$ becomes negligible, that is, equal to zero, which means here, we are not considering the effect of introduction of new products on the old one after time period $T_{1}$. That is, demand rate of the old product is the same throughout the planning period $(0, T)$, and for this case the adoption rate, that is, demand rate, that is, $\lambda(t)=n(t)$, reduces to the classical Fourt and WoodLock model [2]. The objective here is to study the different managerial policies for the model which is under external influence only and its demand is not affected by the introduction of any other 
substitute products. In that case, the total cost per unit time $K(T)$ is given by

$$
\begin{gathered}
K(T)=\frac{A}{T}+\frac{\bar{N} C}{T}\left(1-e^{-p T}\right)+\frac{\bar{N} I C}{p T}\left(1-e^{-p T}\right)-\bar{N} I C e^{-p T}, \\
I(0)=Q=\int_{0}^{T} \lambda(t) d t=\bar{N}\left(1-e^{-p T}\right) .
\end{gathered}
$$

For optimum total cost, the necessary criterion is

$$
\begin{gathered}
\frac{d K(T)}{d T}=0 \\
\Longrightarrow \frac{-A}{T^{2}}+\frac{\bar{N} C p e^{-p T}}{T}-\frac{\bar{N} C\left(1-e^{-p T}\right)}{T^{2}}+\frac{\bar{N} I C e^{-p T}}{T} \\
-\frac{\bar{N} I C\left(1-e^{-p T}\right)}{p T^{2}}+\bar{N} I C p e^{-p T}=0 .
\end{gathered}
$$

Now, for $K(T)$ to be convex:

$$
\begin{aligned}
& \left.\frac{d^{2} K(T)}{d T^{2}}\right|_{T=T^{*}}>0 \\
& \Longrightarrow \frac{2 A}{T^{* 3}}+\frac{2 \bar{N} C\left(1-e^{-p T^{*}}\right)}{T^{* 3}}+\frac{2 \bar{N} I C\left(1-e^{-p T^{*}}\right)}{p T^{* 3}} \\
& >\frac{\bar{N} C p^{2} e^{-p T^{*}}}{T^{*}}+\frac{\bar{N} I p C e^{-p T^{*}}}{T^{* 2}}+\bar{N} I C p^{2} e^{-p T^{*}} .
\end{aligned}
$$

The solution of the equation $d K(T) / d T=0$ gives the optimum value of $T$ provided it satisfies the condition $d^{2} K(T) / d T^{2}>0$. Since cost equation (26) is highly nonlinear, the problem has been solved numerically for given parameter values. The solution gives the optimum value $T^{*}$ of the replenishment cycle time $T$. Once $T^{*}$ is known, the values of optimum order quantity $Q^{*}$ and the optimum cost $K\left(T^{*}\right)$ can easily be obtained from (24) and (23), respectively. The numerical solution for the given base value has been obtained by using software packages LINGO and Excel-Solver.

\section{Solution Procedure}

The solution procedure has been summarized in the following algorithm.

Step 1. Input all parameter values such as unit cost, coefficient of innovation, potential market size, and ordering cost, for each case separately.

Step 2. Compute all possible values of " $T$ " separately for (21) and (26) as the case may be.

Step 3. select the appropriate value of " $T$ " say $T^{*}$ for each case by using (19) and (23) and by satisfying the above stated condition $d^{2} K(T) / d T^{2}>0$.

Step 4. Compute $K\left(T^{*}\right)$ from (19) and (23) \&Q(T* from (10) and (24) for each case separately.
The above steps are used for all replenishment cycles using appropriate parameter values. In order to obtain the appropriate values of " $T$ ", we need to follow the above procedure with the help of LINGO and Excel-Solver software packages.

\section{Numerical Examples}

The effectiveness of the proposed model has been shown by the following numerical examples. A hypothetical example has the following parameter values in appropriate units:

$$
\begin{gathered}
A=\frac{\$ 1100}{\text { order }}, \quad C=\frac{\$ 300}{\text { unit }}, \\
I=0.25, \quad \bar{N}=50000 .
\end{gathered}
$$

The results have been well presented in the following different tables. Also, to prove the validity of the model numerically and to get the appropriate parameter values, the references have been considered as Chanda and Kumar [25], Chandrasekaran and Tellis [34], Sultan et al. [35], Talukdar et al. [36], Van den Bulte and Stremersch [37], Chanda and Kumar [27], Aggarwal et al. [26, 31], Aggarwal et al. [29], and Kumar et al. [30].

(i) The mean value of the coefficient of innovation for a new product usually lies between 0.0007 and 0.03 (Sultan et al. [35]; Talukdar et al. [36]; Van den Bulte and Stremersch [37]).

(ii) The mean value of the coefficient of innovation for a new product is usually 0.01 for developed countries and 0.0003 for developing countries (Talukdar et al. [36]).

4.1. Special Case. A hypothetical example has the following parameter values in appropriate units:

$$
\begin{gathered}
A=\frac{\$ 1100}{\text { order }}, \quad C=\frac{\$ 300}{\text { unit }}, \\
I=0.25, \quad \bar{N}=50000, \quad \theta=0 .
\end{gathered}
$$

\section{Observations}

The results obtained from different numerical tables in Section 4 explain the effect of changes in the system parameters on the optimal values of total cost $K\left(T^{*}\right)$, the optimal cycle length $T^{*}$, and the optimal order quantity $Q\left(T^{*}\right)$. We have observed the following relationship during the numerical exercise.

(a) As the coefficient of innovation increases keeping other parameters constant then the optimal cycle length $T^{*}$ decreases while both the optimal order quantity $Q\left(T^{*}\right)$ and the optimal total cost $K\left(T^{*}\right)$ increases as depicted in Tables 1 and 4 . This is consistent with the reality as more investment on promotion will increase the diffusion of a product in the market resulting in shrinkage of the optimal reorder cycle time as a result optimal cost is increased. 
TABLE 1: Sensitivity analysis on coefficient of innovation " $p$ ”.

\begin{tabular}{lccc}
\hline$p$ & $T^{*}$ & $K\left(T^{*}\right)$ & $Q\left(T^{*}\right)$ \\
\hline 0.001 & 0.86 & 16400 & 39 \\
0.002 & 0.59 & 32705 & 57 \\
0.003 & 0.48 & 48684 & 70 \\
0.004 & 0.41 & 64499 & 81 \\
0.005 & 0.37 & 80211 & 91 \\
0.006 & 0.34 & 95848 & 101 \\
0.007 & 0.31 & 111430 & 109 \\
0.008 & 0.29 & 126967 & 117 \\
0.009 & 0.27 & 142468 & 124 \\
0.01 & 0.26 & 157938 & 131 \\
0.02 & 0.19 & 311593 & 190 \\
\hline
\end{tabular}

For $T_{1}=0.1, \theta=0.0001$.

(b) As the cycle length $T_{1}$, that is, the time of introduction of second product, increases keeping other parameters constant then the optimal cycle length $T^{*}$, optimal order quantity $Q\left(T^{*}\right)$, and the optimal total cost $K\left(T^{*}\right)$ all these three values increase as depicted in Table 2. This is true with the fact that as the time of introduction of second product increases, means maximum demand is satisfied by more number of previous, that is, old products, and it is also obvious that the demand is a decreasing function of time which implies that less demand for more time period leads to increase in optimal cycle length. And since optimal cycle length increases; therefore, it forces the inventory manager to keep more number of inventories to satisfy decreasing demand for longer time period and because more number of inventories are kept for longer time period it leads to increase in the optimal cost (Figure 3).

(c) As the value of $\theta$ increases keeping other parameters constant, then the optimal cycle length $T^{*}$ increases whereas optimal order quantity $Q\left(T^{*}\right)$ and the optimal total cost $K\left(T^{*}\right)$ decreases as depicted in Table 3. This is also true with the fact that as $\theta$ increases means demand of the first product decreases more because more demand is satisfied by its substitute product which is introduced after a certain interval of time, and therefore, less inventories are kept for longer period which leads to decrease in the optimal cost.

\section{Managerial Implications}

The goodwill of any organization is entirely dependent on its effective management and this is possible only when the problem of the organization is analyzed properly from all perspectives. Here, our problem is concerned with the effective management of products which are newly introduced in the market and along with this, the effect of second generation products on the demand of first generation products is also realized; the idea included here is that the effect of substitute products decreases the demand of old products after a certain
TABLE 2: Sensitivity analysis on " $T_{1}$ ”.

\begin{tabular}{lccc}
\hline$T_{1}$ & $T^{*}$ & $K\left(T^{*}\right)$ & $Q\left(T^{*}\right)$ \\
\hline 0.10 & 0.59 & 68778 & 124 \\
0.11 & 0.61 & 69032 & 128 \\
0.12 & 0.63 & 69279 & 131 \\
0.13 & 0.64 & 69520 & 135 \\
0.14 & 0.66 & 69756 & 139 \\
0.15 & 0.67 & 69987 & 143 \\
0.16 & 0.69 & 70213 & 146 \\
0.17 & 0.7 & 70435 & 150 \\
0.18 & 0.72 & 70653 & 153 \\
0.19 & 0.73 & 70866 & 157 \\
0.20 & 0.75 & 71076 & 160 \\
\hline For $\theta=0.001, P$ & 0.005 & &
\end{tabular}

TABLE 3: Sensitivity analysis on " $\theta$ ".

\begin{tabular}{lccc}
\hline$\theta$ & $T^{*}$ & $K\left(T^{*}\right)$ & $Q\left(T^{*}\right)$ \\
\hline 0.019 & 0.38 & 1802327 & 2228 \\
0.020 & 0.41 & 1649195 & 2180 \\
0.021 & 0.44 & 1495228 & 2121 \\
0.022 & 0.48 & 1340344 & 2050 \\
0.023 & 0.52 & 1184432 & 1965 \\
0.024 & 0.58 & 1027337 & 1865 \\
0.025 & 0.65 & 868835 & 1747 \\
0.026 & 0.73 & 708581 & 1605 \\
0.027 & 0.86 & 545998 & 1433 \\
0.028 & 1.07 & 379973 & 1217 \\
0.029 & 1.54 & 207669 & 918 \\
\hline
\end{tabular}

For $T_{1}=0.01, p=0.03, \bar{N}=500000$.

TABLE 4: Sensitivity analysis on coefficient of innovation " $p$ ”.

\begin{tabular}{lccc}
\hline$p$ & $T^{*}$ & $K\left(T^{*}\right)$ & $Q\left(T^{*}\right)$ \\
\hline 0.001 & 0.76 & 17865 & 38 \\
0.002 & 0.54 & 34044 & 54 \\
0.003 & 0.44 & 49942 & 67 \\
0.004 & 0.38 & 65695 & 77 \\
0.005 & 0.34 & 81354 & 86 \\
0.006 & 0.31 & 96946 & 95 \\
0.007 & 0.29 & 112487 & 102 \\
0.008 & 0.27 & 127987 & 110 \\
0.009 & 0.26 & 143453 & 117 \\
0.01 & 0.24 & 158891 & 123 \\
0.02 & 0.17 & 312305 & 178 \\
\hline
\end{tabular}

Special case.

interval of time because of technological innovations and other related factors. Therefore, to overcome this problem, a mathematical model has been developed to know the actual situation of the economic ordering policies which will help the inventory manager to take effective action to maintain the optimal cost. The results obtained in the model create a pool of knowledge on the diffusion processes of innovations 


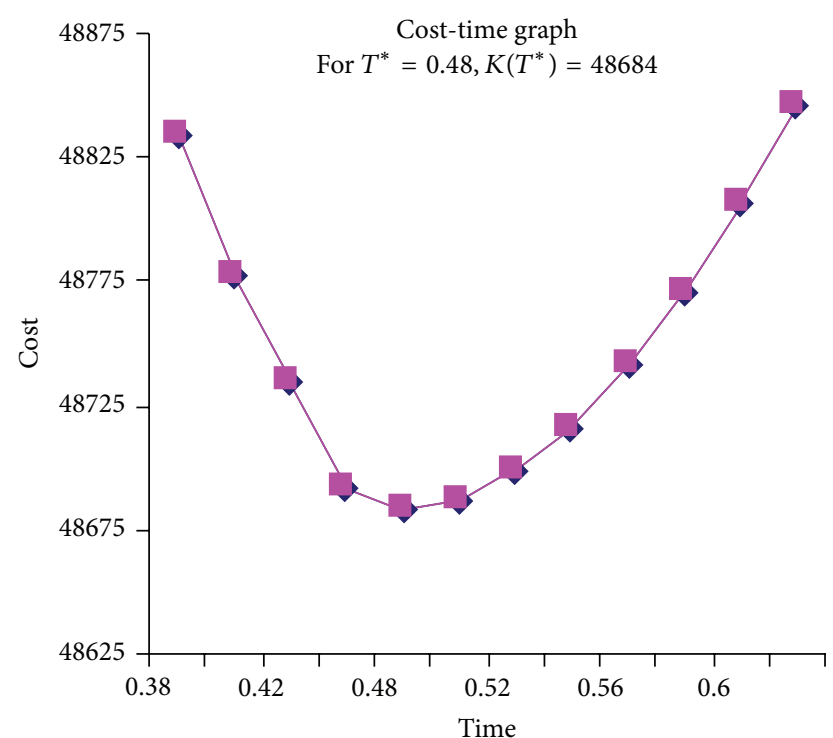

(a)

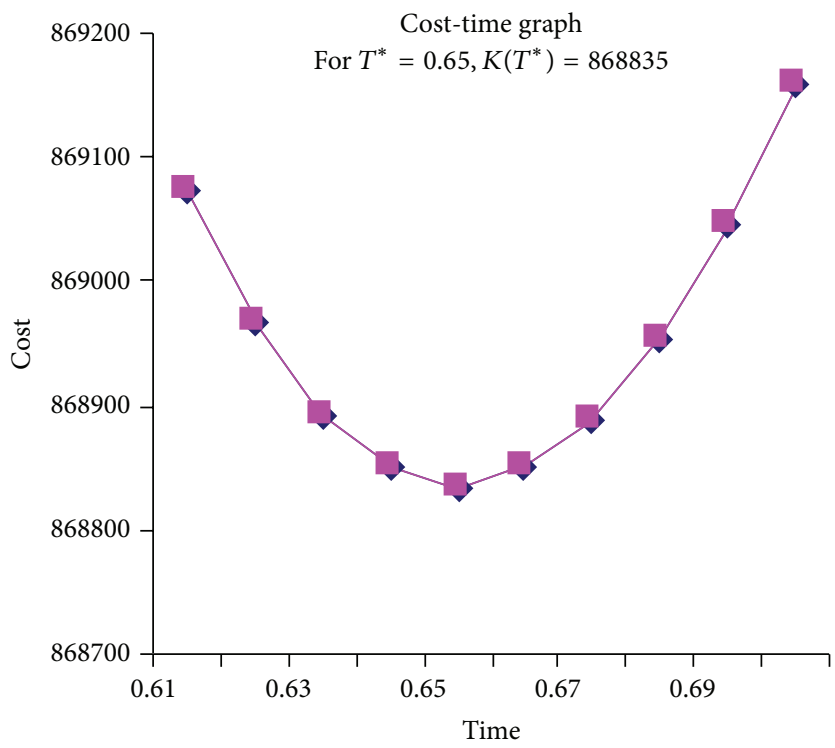

(c)

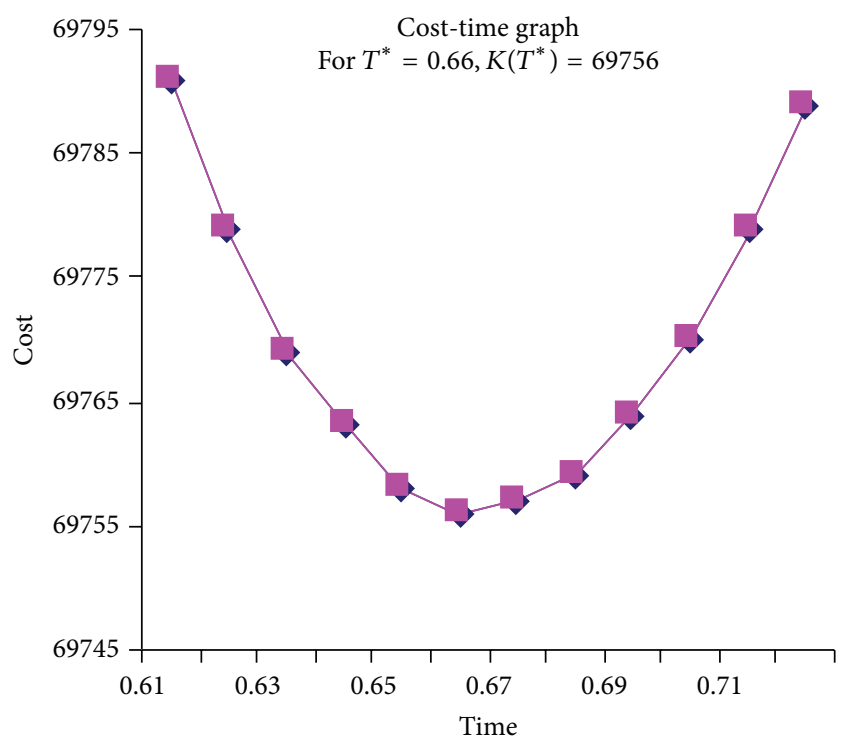

(b)

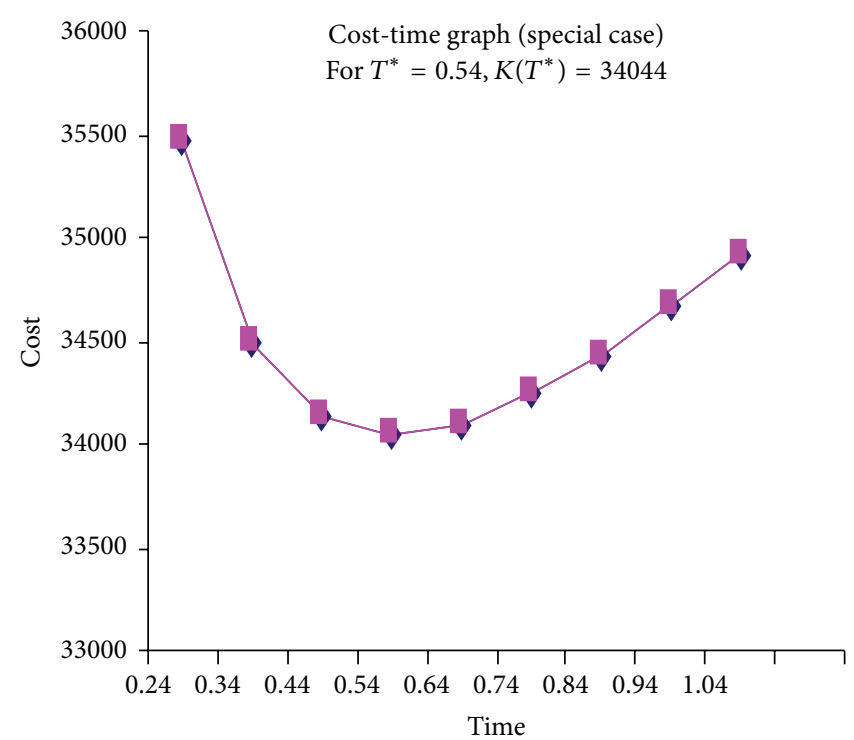

(d)

FIGURE 3: Cost-time graphs showing convexity of the cost functions.

and its effective management which are most valuable to both researchers and managers. For managers, this pool of knowledge is important because it provides useful tools and useful information for managing and scheduling the inventories of new products when its demand is affected by the generation of other new products which substitute products after a certain time period. The uniqueness of this model is that how the inventory manager should keep the optimal cycle time of any fixed lot size of one product entering into the inventory system when its substitute product enters into the system after a fixed interval so that optimal cost is maintained and the cost of inventory obsolescence is minimized.

\section{Conclusion}

The technological breakthrough is constantly being experienced in various products across the globe which is necessary for the products to gain competitive advantage. There are various marketing strategies to promote and establish products which are newly introduced into the market, but keeping its inventories efficiently and effectively play a greater role. Here, the role of inventory models becomes significant. The primary objective of developing inventory models is to take efficient action concerned with economic ordering policies and to understand well the behaviour of parameters associated with it. In this paper, a mathematical model has 
been developed for obtaining the Economic Order Quantity (EOQ) in which the demand of the product is assumed to follow an innovation diffusion process as proposed by Fourt and WoodLock [2], and along with, this the demand of the product decreases after a certain interval of time because of the introduction of its substitute product. Here, the model analyses the situation when demand of the previous product is affected by introducing second generation product. There are few inventory models such as Chern et al. [28], Chanda and Kumar [25], Aggarwal et al. [26], and Chanda and Kumar [27] which capture the sensitive nature of marketing parameters but have not incorporated the idea of the effect of introduction of second generation product. This paper attempts to bridge this gap. The approach of this paper is to obtain economic ordering policies of a new product when its substitute product enters into the market after a certain time period. A special case has also been discussed which excludes the effect of substitute products on the inventory policies of old products. Numerical examples with sensitivity analyses are presented to illustrate the model properly. The results obtained are largely consistent with what we observe empirically. A simple solution procedure in the form of algorithm is presented to determine the optimal cycle time and optimal order quantity of the cost function. The proposed model can be extended for backorders, quantity discount, partial lost sales, and so forth, and it can also be extended to solve by different approaches such as geometric programming approach, and genetic algorithm approach. At the same time, future research should also focus on developing some alternative approach to obtain the optimal analytical solution of the highly nonlinear cost function which we have solved numerically.

\section{Acknowledgments}

The research presented in this paper was carried out at the Department of Operational Reseach, Faculty of Mathematical Sciences, University of Delhi. The commercial identities mentioned in the paper such as LINGO and Excel-Solver software have only been used for the numerical analysis of the model discussed in the paper which is only for the academic purpose. The authors of this paper do not have any direct financial relation with the commercial identities mentioned in the paper and there is no conflict of interests regarding financial gains for all the authors.

\section{References}

[1] E. Rogers, Diffusion of Innovations, Free Press, New York, NY, USA, 3rd edition, 1983.

[2] L. A. Fourt and J. W. WoodLock, "Early prediction of Market success for new grocery products," Journal of Marketing, vol. 26, no. 2, pp. 31-38, 1960.

[3] J. C. Fisher and R. H. Pry, "A simple substitution model of technological change," Technological Forecasting and Social Change, vol. 3, no. C, pp. 75-88, 1971.

[4] F. M. Bass, "A new product growth for model consumer durables," Management Science, vol. 50, no. 12, pp. 1825-1832, 2004.
[5] R. Peres, E. Muller, and V. Mahajan, "Innovation diffusion and new product growth models: a critical review and research directions," International Journal of Research in Marketing, vol. 27, no. 2, pp. 91-106, 2010.

[6] P. M. Parker, "Aggregate diffusion forecasting models in marketing: a critical review," International Journal of Forecasting, vol. 10, no. 2, pp. 353-380, 1994.

[7] E. M. Rogers, Diffusion of Innovations, Free Press, New York, NY, USA, 4th edition, 1995.

[8] R. Peres, E. Muller, and V. Mahajan, "Innovation diffusion and new product growth models: a critical review and research directions," International Journal of Research in Marketing, vol. 27, no. 2, pp. 91-106, 2010.

[9] V. Mahajan, E. Muller, and Y. Wind, New-Product Diffusion Models, Kluwer Academic Publishers, Boston, Mass, USA, 2000.

[10] F. Cheng and S. P. Sethi, "Periodic review inventory model with demand influenced by promotion decisions," Management Science, vol. 45, no. 11, pp. 1510-1523, 1999.

[11] S. Kalish, "A new product adoption model with price advertising and uncertainty," Management Science, vol. 31, no. 12, pp. 1569$1585,1985$.

[12] V. Mahajan and A. P. Robert, "Innovation diffusion in a dynamic potential adopter population," Management Science, vol. 24, no. 15, pp. 1589-1597, 1978.

[13] M. N. Sharif and K. Ramanathan, "Polynomial innovation diffusion models," Technological Forecasting and Social Change, vol. 21, no. 4, pp. 301-323, 1982.

[14] M. N. Sharif and K. Ramanathan, "Binomial innovation diffusion models with dynamic potential adopter population," Technological Forecasting and Social Change, vol. 20, no. 1, pp. 63-87, 1981.

[15] J. A. Norton and F. M. Bass, "A diffusion theory model of adoption and substitution for successive generation of hightechnology products," Management Science, vol. 33, no. 9, pp. 1069-1086, 1987.

[16] V. Mahajan and E. Muller, "Timing, diffusion, and substitution of successive generations of technological innovations: the IBM mainframe case," Technological Forecasting and Social Change, vol. 51, no. 2, pp. 109-132, 1996.

[17] M. W. Speece and D. L. Maclachlan, "Application of a multigeneration diffusion model to milk container technology," Technological Forecasting and Social Change, vol. 49, no. 3, pp. 281-295, 1995.

[18] P. J. Danaher, B. G. S. Hardie, and W. P. Putsis Jr., "Marketingmix variables and the diffusion of successive generations of a technological innovation," Journal of Marketing Research, vol. 38, no. 4, pp. 501-514, 2001.

[19] T. Islam and N. Meade, "The diffusion of successive generations of a technology: a more general model," Technological Forecasting and Social Change, vol. 56, no. 1, pp. 49-60, 1997.

[20] N. Kim, D. R. Chang, and A. D. Shocker, "Modeling intercategory and generational dynamics for a growing information technology industry," Management Science, vol. 46, no. 4, pp. 496-512, 2000.

[21] B. Bayus, "The dynamic pricing of next generation consumer durables," Marketing Science, vol. 11, no. 3, pp. 251-265, 1992.

[22] A. K. Bardhan and U. Chanda, "A model for first and substitution adoption of successive generations of a product," International Journal of Modelling and Simulation, vol. 28, no. 4, pp. 487-494, 2008. 
[23] U. Chanda and A. K. Bardhan, "Dynamic optimal advertising expenditure strategies of two successive generations of consumer durables," in Proceedings of the International Conference on Modelling, Computation and Optimization held during January 2008 in the venue SQC \& OR Unit, Indian Statistical Institute, New Delhi, India, 2008.

[24] K. A. Bardhan and U. Chanda, "A mathematical model for diffusion of products with multiple generations," International Journal of Operational Research, vol. 4, no. 2, pp. 214-229, 2009.

[25] U. Chanda and A. Kumar, "Economic order quantity model with demand influenced by dynamic innovation effect," International Journal of Operational Research, vol. 11, no. 2, pp. 193-215, 2011.

[26] K. K. Aggarwal, C. K. Jaggi, and A. Kumar, "Economic order quantity model with innovation diffusion criterion having dynamic potential market size," International Journal of Applied Decision Sciences, vol. 4, no. 3, pp. 280-303, 2011.

[27] U. Chanda and A. Kumar, "Economic order quantity model on inflationary conditions with demand influenced by innovation diffusion criterion," International Journal of Procurement Management, vol. 5, no. 2, pp. 160-177, 2012.

[28] M.-S. Chern, J.-T. Teng, and H.-L. Yang, "Inventory lot-size policies for the bass diffusion demand models of new durable products," Journal of the Chinese Institute of Engineers, vol. 24, no. 2, pp. 237-244, 2001.

[29] K. K. Aggarwal and A. Kumar, "An inventory model for new product when demand follows dynamic innovation process having dynamic potential market size," International Journal of Strategic Decision Sciences, vol. 3, no. 4, pp. 78-99, 2012.

[30] A. Kumar, K. K. Aggarwal, and U. Chanda, "Economic order quantity model under fuzzy sense with demand follows Bass's innovation diffusion process," International Journal of Advanced Operations Management, vol. 5, no. 3, pp. 261-281, 2013.

[31] K. K. Aggarwal, C. K. Jaggi, and A. Kumar, "Economic order quantity model under fuzzy sense when demand follows innovation diffusion process having dynamic potential market size," International Journal of Services and Operations Management, vol. 13, no. 3, pp. 361-391, 2012.

[32] V. Mahajan and R. A. Peterson, Models of Innovation Diffusion, Sage, 1985.

[33] E. Ruiz-Conde, P. S. H. Leeflang, and J. E. Wieringa, "Marketing variables in macro-level diffusion models," Journal fur Betriebswirtschaft, vol. 56, no. 3, pp. 155-183, 2006.

[34] D. Chandrasekaran and G. J. Tellis, "A critical review of marketing research on diffusion of new products," Review of Marketing Research, pp. 39-80, 2007.

[35] F. Sultan, J. U. Farley, and D. R. Lehmann, "A meta-analysis of diffusion models," International Journal of Forecasting, vol. 27, no. 1, pp. 70-77, 1990.

[36] D. Talukdar, K. Sudhir, and A. Ainslie, "Investigating new product diffusion across products and countries," Marketing Science, vol. 21, no. 1, pp. 97-114, 2002.

[37] C. van den Bulte and S. Stremersch, "Social contagion and income heterogeneity in new product diffusion: a meta-analytic test," Marketing Science, vol. 23, no. 4, pp. 530-544, 2004.

[38] G. L. Lilien, P. Kotler, and K. S. Moorthy, Marketing Models, Prentice-Hall of India Private, New Delhi, India, 1999. 


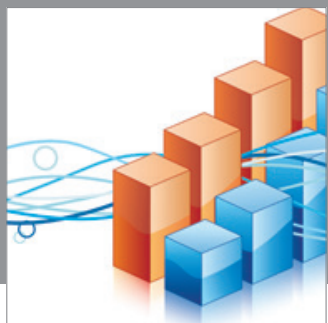

Advances in

Operations Research

mansans

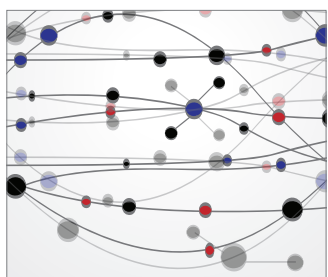

The Scientific World Journal
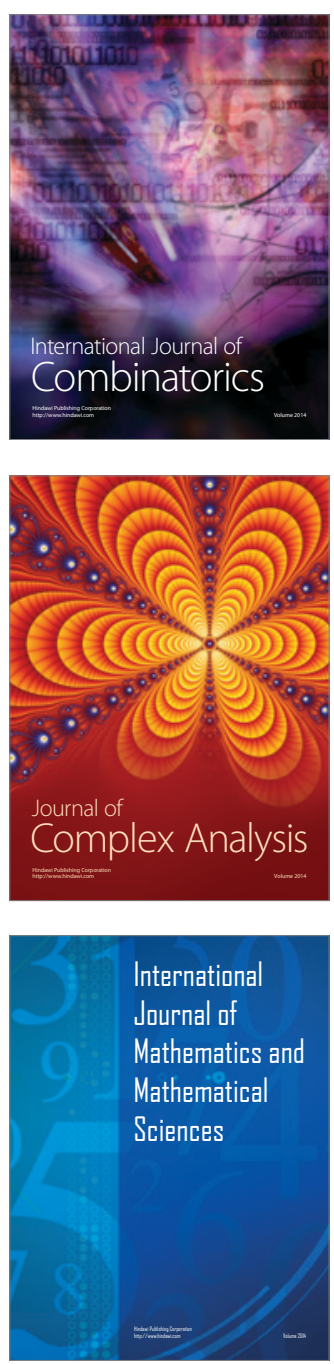
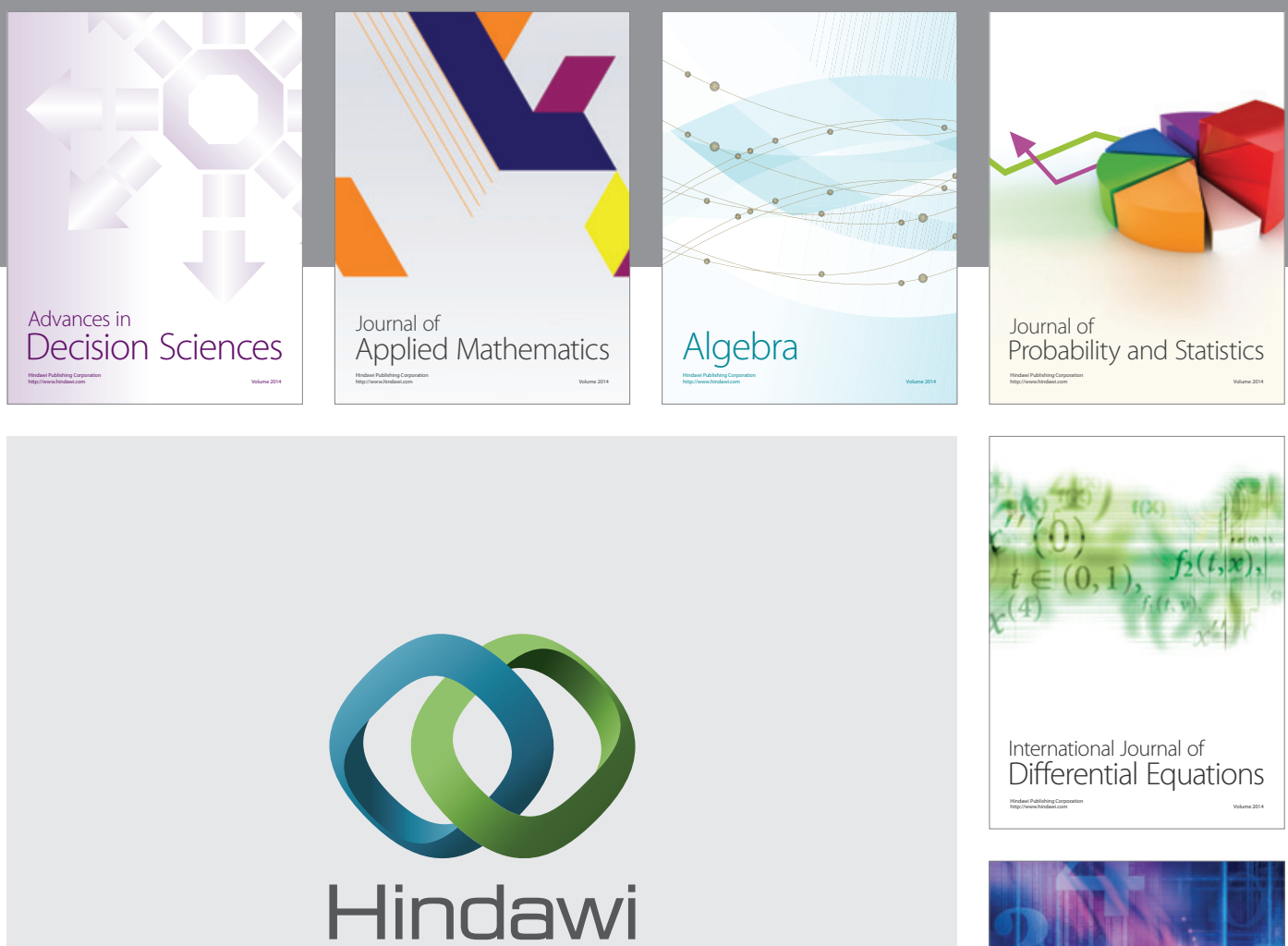

Submit your manuscripts at http://www.hindawi.com
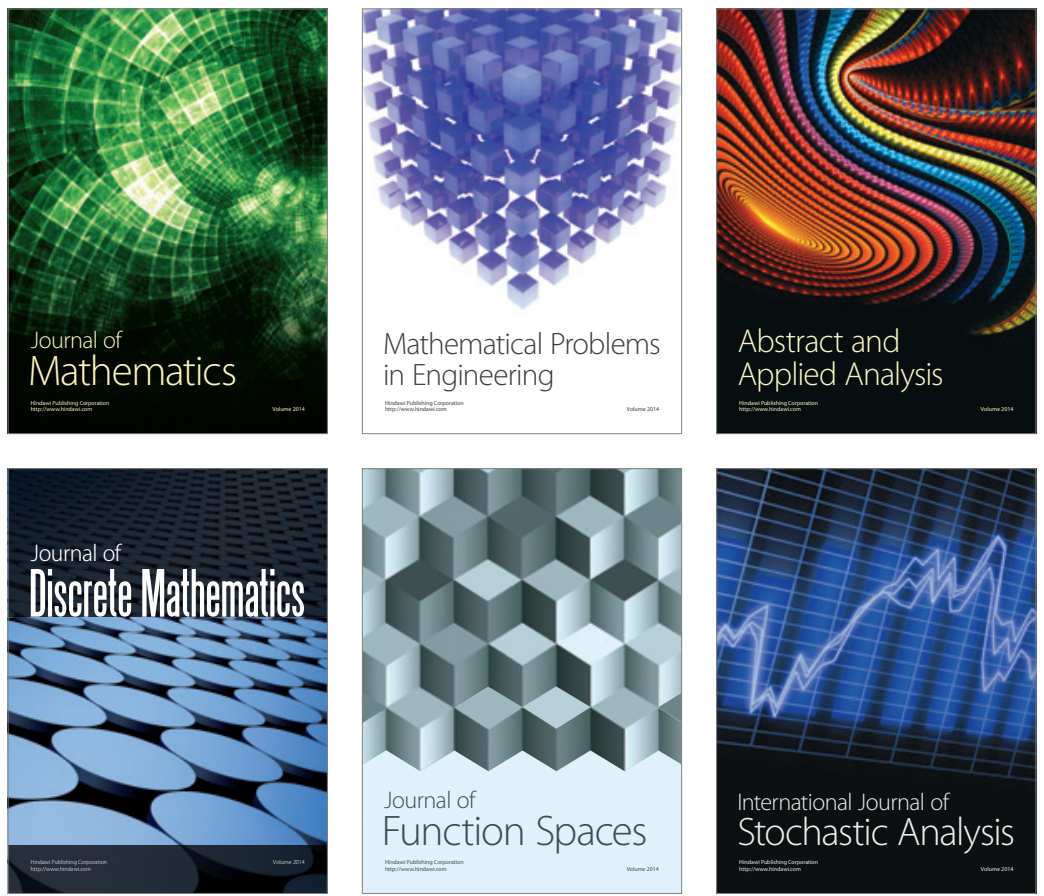

Journal of

Function Spaces

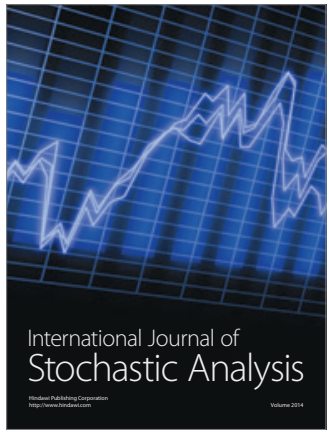

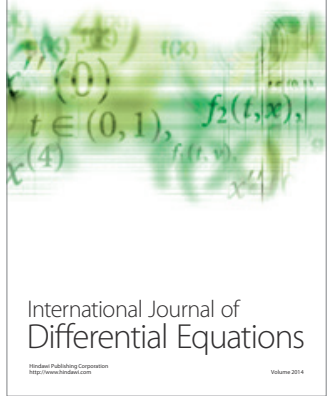
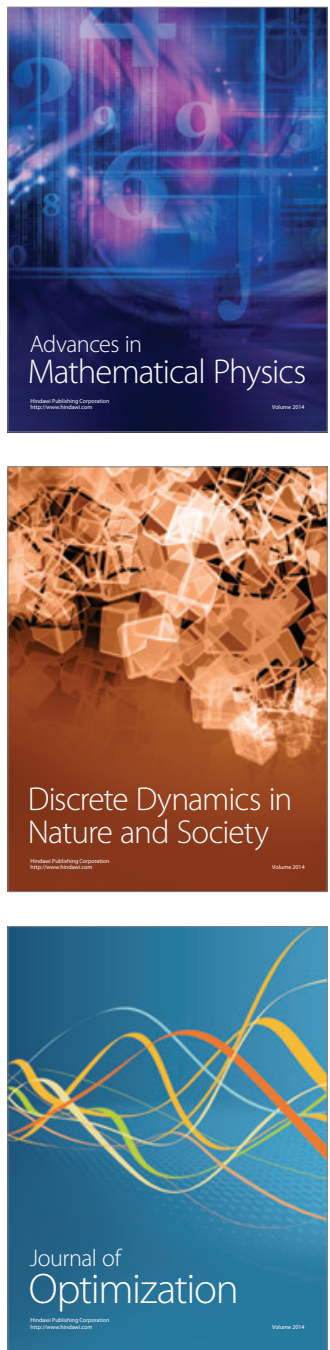